\title{
Co-expression of AaPMT and AaTRI effectively enhances the yields of tropane alkaloids in Anisodus acutangulus hairy roots
}

\author{
Guoyin Kai", Sheng Yang, Xiuqin Luo, Wentao Zhou, Xueqing Fu, Ang Zhang, Yan Zhang and Jianbo Xiao
}

\begin{abstract}
Background: Tropane alkaloids (TA) including anisodamine, anisodine, hyoscyamine and scopolamine are a group of important anticholinergic drugs with rapidly increasing market demand, so it is significant to improve TA production by biotechnological approaches. Putrescine N-methyltransferase (PMT) was considered as the first ratelimiting upstream enzyme while tropinone reductase I (TRI) was an important branch-controlling enzyme involved in TA biosynthesis. However, there is no report on simultaneous introduction of PMT and TRI genes into any TAproducing plant including Anisodus acutangulus (A. acutangulus), which is a Solanaceous perennial plant that is endemic to China and is an attractive resource plant for production of TA.

Results: In this study, 21 AaPMT and AaTRI double gene transformed lines (PT lines), 9 AaPMT single gene transformed lines ( $P$ lines) and 5 AaTRI single gene transformed lines (T lines) were generated. RT-PCR and real-time fluorescence quantitative analysis results revealed that total AaPMT (AaPMT T) and total AaTRI (AaTRI T) gene transcripts in transgenic PT, P and T lines showed higher expression levels than native AaPMT (AaPMT E) and AaTRl (AaTRI E) gene transcripts. As compared to the control and single gene transformed lines (P or T lines), PT transgenic hairy root lines produced significantly higher levels of TA. The highest yield of TA was detected as 8.104 $\mathrm{mg} / \mathrm{g} \mathrm{dw}$ in line PT18, which was 8.66, 4.04, and 3.11-times higher than those of the control $(0.935 \mathrm{mg} / \mathrm{g} \mathrm{dw})$, P3 (highest in P lines, $2.004 \mathrm{mg} / \mathrm{g} \mathrm{dw}$ ) and T12 (highest in T lines, $2.604 \mathrm{mg} / \mathrm{g} \mathrm{dw}$ ), respectively. All the tested samples were found to possess strong radical scavenging capacity, which were similar to control.

Conclusion: In the present study, the co-expression of AaPMT and AaTRI genes in A. acutangulus hairy roots significantly improved the yields of TA and showed higher antioxidant activity than control because of higher total TA content, which is the first report on simultaneous introduction of PMT and TRI genes into TA-producing plant by biotechnological approaches.
\end{abstract}

\section{Background}

Tropane alkaloids (TA) including anisodamine, anisodine, hyoscyamine and scopolamine are widely used as anticholinergic agents, which act on the parasympathetic nervous system and exclusively exist in Solanaceous plants such as Anisodus, Atropa, Datura, Duboisia, Hyoscyamus, and Scopolia [1-3]. Specially, anisodamine is not as toxic as atropine and has fewer negative effects on the central nervous system than scopolamine [4]. Furthermore, anisodamine and anisodine also showed protective effects on acute lung injury induced by oleic

\footnotetext{
* Correspondence: gykai@yahoo.com.cn

Laboratory of Plant Biotechnology, College of Life and Environment Sciences, Shanghai, Normal University, Shanghai 200234, China
}

acid and microvascular injury of acute renal failure in rats $[5,6]$.

The hairy root culture system offered many advantages such as high genetic stability, rapid and hormonefree growth, which was considered as a promising way to produce bioactive components from the medicinal plants $[7,8]$. It has been proven that the application of small scale jar fermenters for culturing hairy roots induced from several Solanaceous plants is a very prospective method for production of TA [9-12]. Now TA biosynthetic pathway and key enzyme gene identification have been made clear, so it is possible to enhance TA production in the hairy root culture by biotechnology methods [13-15].

\section{() Biomed Central}


A. acutangulus is a Chinese native medicinal plant with higher content of total alkaloids and it has been considered as an attractive plant resource for TA yield $[13,16]$. But the natural amounts of anisodamine, anisodine and scopolamine are not very high in A. acutangulus. However, these alkaloids are all important in phytomedicine with rapid increasing market demand. Thus, it is essential to improve their yields by biotechnological approaches. [17,18].

In TA biosynthetic pathway, Putrescine $N$-methyltransferase (PMT) was considered as the first rate-limiting upstream enzyme while tropinone reductase I (TRI) was an important branch-controlling enzyme (Figure 1). Hence, these two genes are promising target sites for genetic engineering to increase TA in $A$. acutangulus hairy root cultures. Recently, the cDNAs of Putrescine $\mathrm{N}$-methyltransferase (AaPMT) and tropinone reductase I (AaTRI) of $A$. acutangulus have been successfully cloned by our laboratory $[3,19]$. However, there is no report on simultaneous introduction of PMT and TRI into any TA-producing plant including $A$. acutangulus. In this paper, $A a P M T$ and $A a T R I$ genes were simultaneously introduced into $A$. acutangulus hairy roots for the first time.

\section{Results}

Identification of transformed root lines through PCR analysis

Three plasmids containing the cDNAs encoding AaPMT and/or AaTRI, driven by CaMV $35 \mathrm{~S}$ promoter, were separately introduced into $A$. acutangulus using disarmed A. tumefaciens C58C1 strain. In total, 25 AaPMT single gene transformed lines (P lines), 19 AaTRI single gene transformed lines (T lines) and 46 AaPMT and AaTRI double gene transformed lines (PT lines) were generated, respectively (Table 1 ). The hairy root lines were subcultured for about 4 weeks in hormone-free, B5 solid medium with cefotaxime. At last, $17 \mathrm{P}, 15 \mathrm{~T}$ and

\section{Putrescine

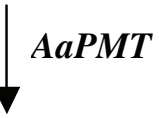

N-methylputrescine

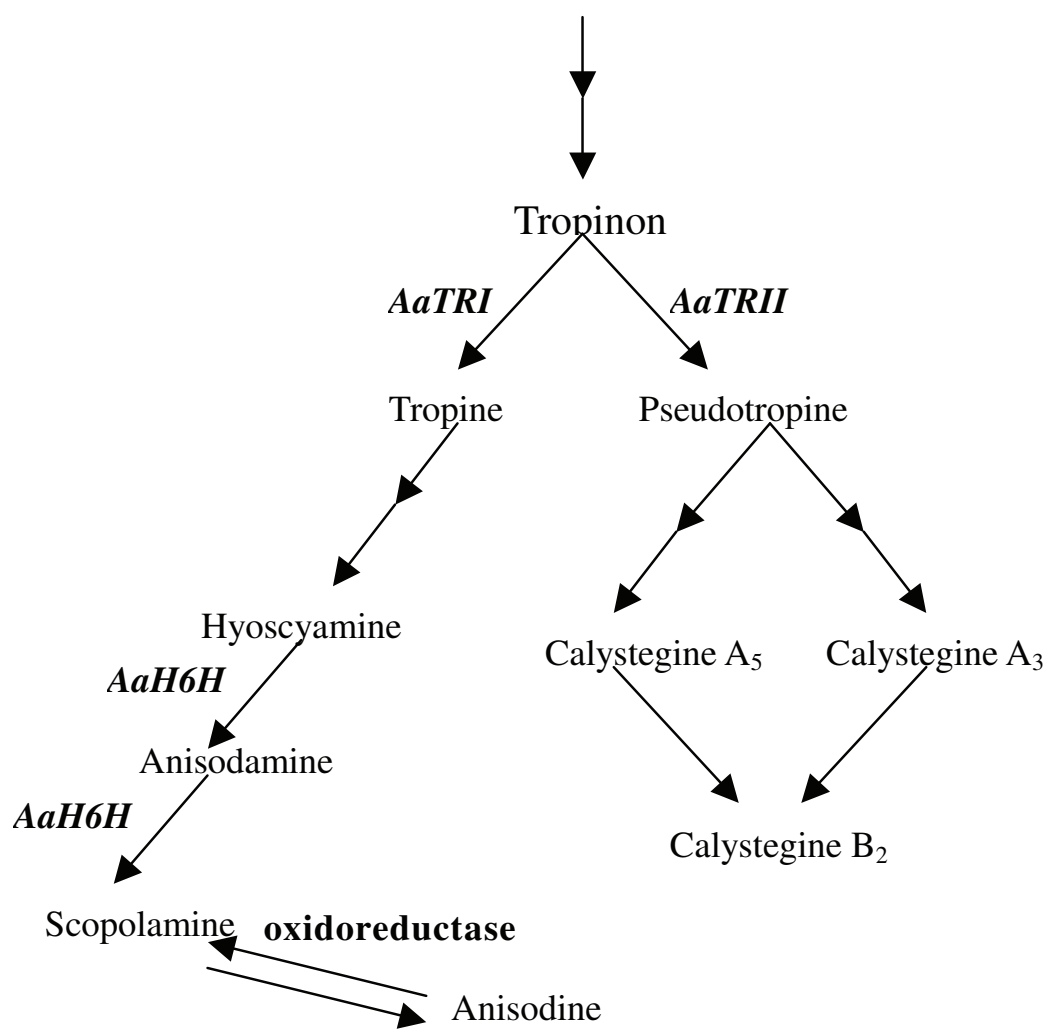

Figure 1 Schematic biosynthetic pathway of tropane alkaloid in A. acutangulus. From the picture, we know that anisodine comes from the change of scopolamine (result is not present). 
Table 1 Positive clones of transgenic hairy roots.

\begin{tabular}{ccccc}
\hline \multicolumn{5}{c}{ Number of root lines } \\
\hline Gene constructs & Total & Hygromycin-resistant & PCR-positive & Established root lines \\
\hline AaPMT & 25 & 17 & 9 & P1 P2 P3 P5 P6 P7 P9 P12 P16 \\
\hline AaTRI & 19 & 15 & 5 & T3 T4 T5 T6 T12 \\
\hline AaPMT-AaTRI & 46 & 36 & 21 & PT2 PT3 PT4 PT5 PT6 PT7 PT10 PT12 PT13 PT15 PT17 PT18 PT19 \\
& & & & PT20 PT21 PT22 PT24 PT25 PT26 PT27 PT28 \\
\hline
\end{tabular}

36 PT hygromycin-resistant hairy root lines were obtained (Table 1). DNA of all the independent hairy roots was isolated and used for PCR analysis using primers specially designed to overlap part of the AaPMT or AaTRI and the CaMV 35S promoter sequences. The plasmid $1304^{+}$-AaPMT or $1304^{+}-$AaTRI was used as positive control (PC) and control hairy-root lines generated from blank-vector transformations were used as BC. In total, the PCR-positive clones amounted to $52.94 \%$ (9/17), 33.33\% (5/15) and 58.33\% (21/36) for P, $\mathrm{T}$ and PT lines, respectively. None of the checked DNA bands was detected from BC lines (Figure 2A).

\section{Morphological characterization of the transgenic hairy roots}

In this experiment, the transgenic hairy roots had two main morphology forms. One form was abnormal and looked brownish, thick with short branches such as PT3, T3 and T5. This kind of hairy root has been abnormal with slow growth since it was cultured on solid medium during the stage of sterilization (Figure 3A 1-4). Contrarily, most of transgenic hairy roots belonged to another form, which were normal and looked yellowish or light brownish with whiter slender branched. These hairy root clones have been always normal from the stage of sterilization in the culture dishes to the stage of rapid growth in the flasks (Figure 3B 14).

\section{Analysis of the transcript level of AaPMT and AaTRI}

Total RNA was isolated from the positive root lines and RT-PCR, real-time fluorescence quantitative analysis were used to determine the expression levels of $A a P M T$ and AaTRI. As shown in Figure $2 \mathrm{~B}$ and $2 \mathrm{C}$, the different expression levels illustrated that total AaPMT gene (AaPMT T) and total AaTRI gene (AaTRI T) transcripts in transgenic PT, $\mathrm{P}$ lines and $\mathrm{T}$ lines exhibited higher expression than the native AaPMT gene (AaPMTE) and native $A a T R I$ gene $(A a T R I E)$ transcripts. Moreover, the expression patterns of AaPMTE and AaTRI $E$ in the above transgenic lines showed similar levels with $A a P M T$ $T$ and AaTRI T in BC lines. On the contrary, the AaPMT $T$ and AaTRI $T$ transcripts in the P, T and PT lines had higher transcript levels, which demonstrated that all the expression cassettes of the cDNAs encoding AaPMT and/or AaTRI were introduced into A. acutangulus and expressed at varying degrees in corresponding transgenic lines.

Two independent transgenic lines with AaPMT and AaTRI genes, two lines with AaPMT gene and two lines with AaTRI gene were chosen (Figure 2C). The average expression levels of AaPMT and AaTRI gene in PT6 and PT18 were 13.95-fold and 29.63-fold higher when compared with control, respectively. In P3 and P9, the mean expression level of AaPMT gene was 10.93-fold higher as compared to control. In T4 and T12, the expression levels of AaTRI gene on average were 17.59fold higher when compared with non-transgenic clones.

\section{TA profile in transgenic hairy roots}

The contents of TA in A. acutangulus hairy root lines were analyzed by HPLC. Three independent samples extracted from the transgenic lines and the control lines were tested with SPSS software. One sample $t$ test was used to identify the accumulations of TA which showed significant changes in different lines and control. The capacities of transgenic root lines to yield TA were shown in Figure 4. P lines showed higher level of TA content than control $(0.935 \mathrm{mg} / \mathrm{g} \mathrm{dw})$, which ranged from 1.151 to $2.004 \mathrm{mg} / \mathrm{g} \mathrm{dw}$ (Figure 4A, 5B and 5E). T lines also produced larger level of TA $(1.682 \mathrm{mg} / \mathrm{g} \mathrm{dw})$ than the control (Figure $5 \mathrm{C}$ and $5 \mathrm{E}$, Table 2). Specially, the yield of TA in line T12 reached to $2.604 \mathrm{mg} / \mathrm{g} \mathrm{dw}$ (Figure 4B). The average content of TA in PT lines was significantly enhanced, which was much higher than the average content of the control. The levels of TA in PT lines were within the range from 0.263 to $8.104 \mathrm{mg} / \mathrm{g}$ $\mathrm{dw}$. The highest yield of TA was detected as $8.104 \mathrm{mg} / \mathrm{g}$ $\mathrm{dw}$ in line PT18, which was 8.66, 4.04, and 3.11-times higher than those of the control $(0.935 \mathrm{mg} / \mathrm{g} \mathrm{dw}), \mathrm{P} 3$ (highest in P lines, $2.004 \mathrm{mg} / \mathrm{g} \mathrm{dw}$ ) and T12 (highest in $\mathrm{T}$ lines, $2.604 \mathrm{mg} / \mathrm{g} \mathrm{dw}$ ) (Figure $4 \mathrm{C}, 5 \mathrm{D}$ and $5 \mathrm{E}$ ). The accumulations of scopolamine and anisodine were obviously improved in PT18 $(\mathrm{P}<0.001)$. The yields of scopolamine and anisodine in PT18 were 49-folds and 19- folds higher than the amounts in the BC line, respectively. Moreover, the content of single alkaloid among all hairy root lines was in accordance with the 


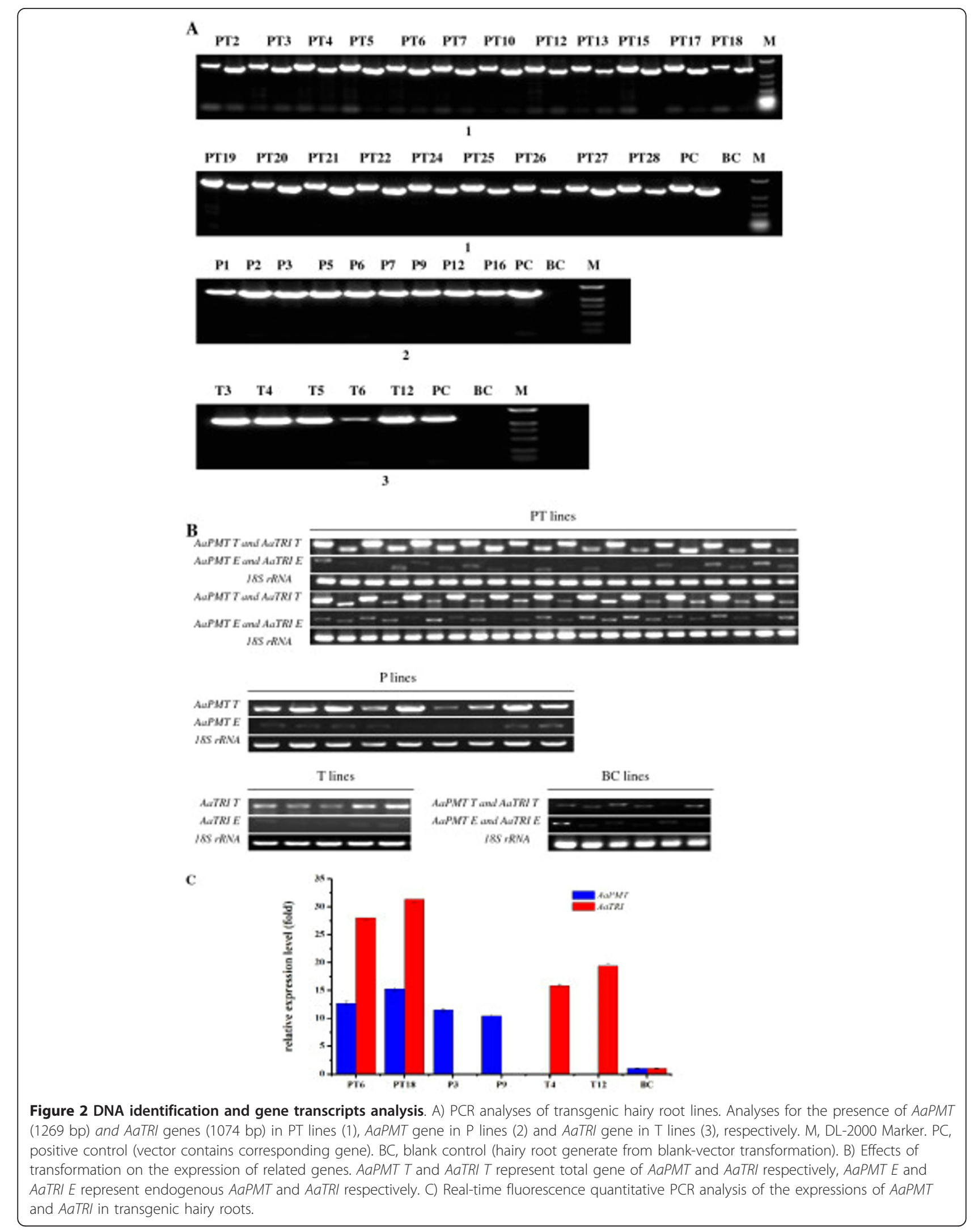




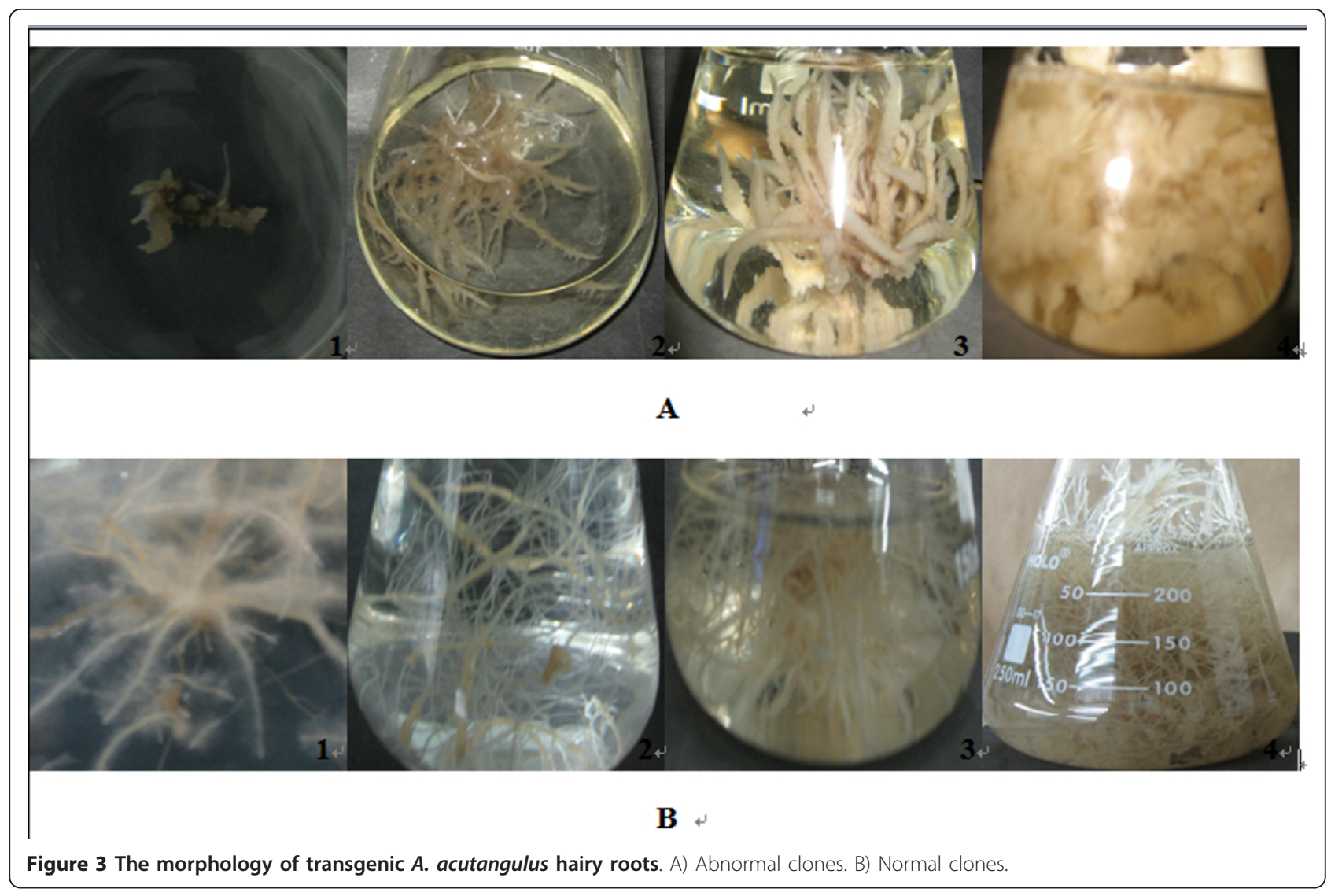

content of TA (Figure 4A, B and 4C). For example, the content of TA in line PT18 was significantly higher compared with that in the control lines $(\mathrm{P}<0.001)$. So the contents of four alkaloids in line PT18 were also much higher than control. The result above confirmed that biotechnological approach was a high-efficiency way to enhance the production of tropane alkaloids.

The difference of average yields of TA in P, T, PT, and $\mathrm{BC}$ lines was showed in Table 2. It illustrated that the content of TA in PT lines $(2.395 \mathrm{mg} / \mathrm{g} \mathrm{dw})$ was the highest, when compared with $\mathrm{T}$ lines $(1.682 \mathrm{mg} / \mathrm{g} \mathrm{dw})$, $\mathrm{P}$ lines $(1.558 \mathrm{mg} / \mathrm{g} \mathrm{dw})$ and $\mathrm{BC}$ lines $(0.935 \mathrm{mg} / \mathrm{g} \mathrm{dw})$. The average content of hyoscyamine in PT lines (1.914 $\mathrm{mg} / \mathrm{g} \mathrm{dw})$ was much higher than that of BC lines $(0.829$ $\mathrm{mg} / \mathrm{g} \mathrm{dw})$, but there is no remarkable difference between $\mathrm{T}(1.376 \mathrm{mg} / \mathrm{g} \mathrm{dw})$ and $\mathrm{P}$ lines $(1.300 \mathrm{mg} / \mathrm{g} \mathrm{dw})$. The average content of anisodine in PT lines $(0.167 \mathrm{mg} / \mathrm{g}$ $\mathrm{dw})$ showed further higher than that of BC lines $(0.0218$ $\mathrm{mg} / \mathrm{g} \mathrm{dw})$. The average content of anisodine was almost the same between $\mathrm{T}(0.104 \mathrm{mg} / \mathrm{g} \mathrm{dw})$ and $\mathrm{P}$ lines $(0.0937 \mathrm{mg} / \mathrm{g} \mathrm{dw})$. To scopolamine, its average content in PT lines was $0.12 \mathrm{mg} / \mathrm{g} \mathrm{dw}$, which also showed much higher than the content in BC lines $(0.0106 \mathrm{mg} / \mathrm{g} \mathrm{dw})$. It was improved by inconceivable 11.32 times compared to the $\mathrm{BC}$ lines.

\section{Antioxidant activity analysis of transgenic hairy roots}

The antioxidant activity of TA from hairy roots was estimated by measuring DPPH radical scavenging in this study. As shown in Figure 6, all the tested samples were found to possess strong radical scavenging capacity, which were similar to control.

\section{Discussion}

TA production in A. acutangulus hairy root cultures was indeed enhanced by biotechnology approach. However, in present study, considerable variation in morphology between different lines was observed, which was similar to the result reported by Jouhikainen et al [20]. The change of external conditions such as the nuances of ingredient in different 1/2 MS liquid nutrient media, the nuance of temperature in the gyratory shaker and the diversification of internal conditions may lead to the different root morphologies. [21]. However, in our experiment, the yields of TA in abnormal hairy roots were higher than those of normal ones. But they would be broken down when inoculated in liquid medium for some time and they were not routinely subcultured. The results implied that root morphology could lead to the content change of secondary metabolite production [1]. 


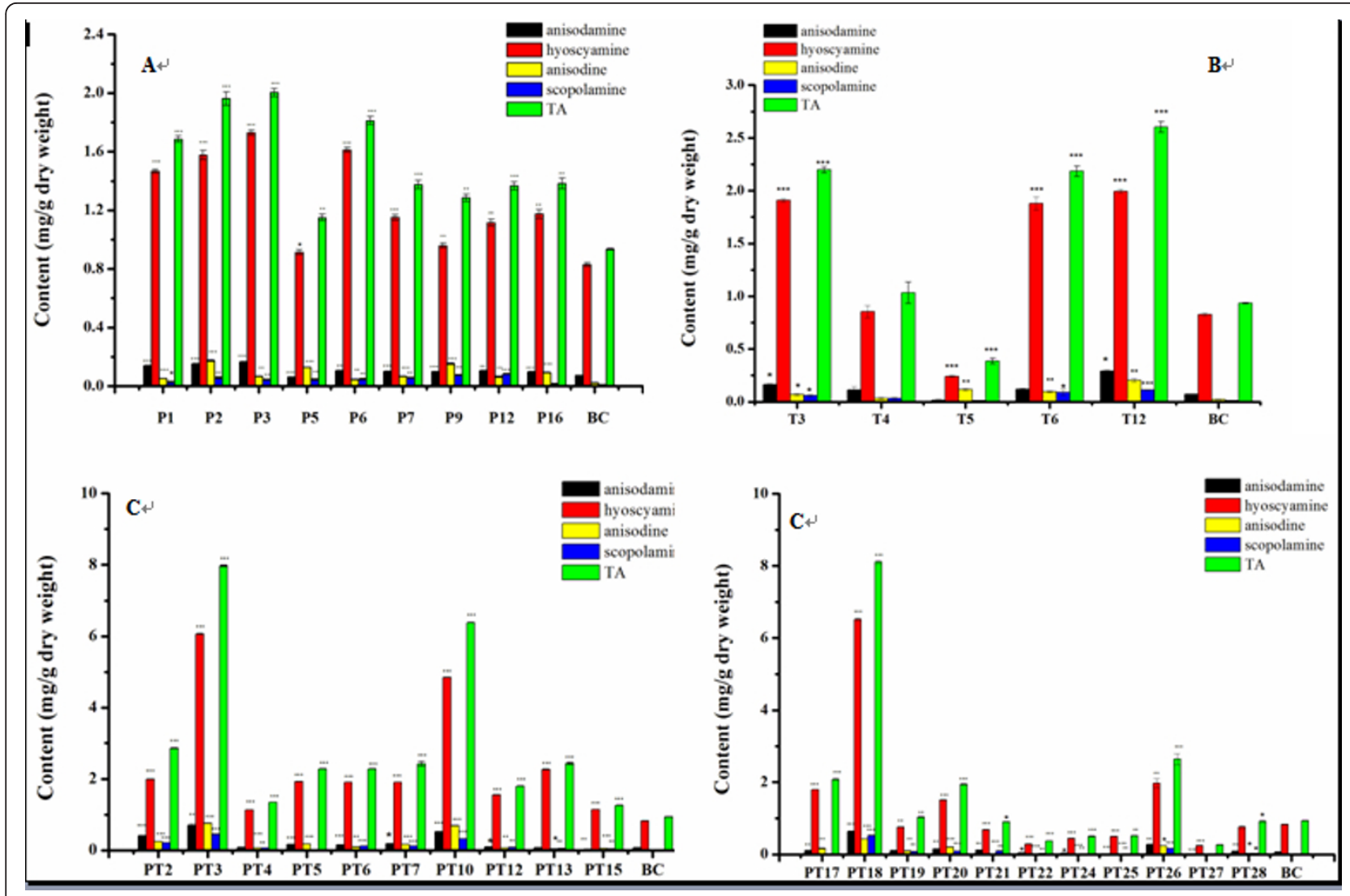

Figure 4 TA production analyzed by HPLC. A) TA content in transgenic P lines. B) TA content in transgenic T lines. C) TA content in transgenic PT lines. BC, control hairy root cultures generate from blank-vector transformation. The values are means \pm S.D of triplicate analyses. $*^{*}, *^{*}$, and ${ }^{* *}$ Significant difference at $P<0.05,0.01$, and 0.001 respectively.

The expression levels of the AaPMT $T$ varied from line to line but correlated with their corresponding content of TA in P lines. The average content of TA in P lines showed higher than that of $\mathrm{BC}$ lines. Moreover, the contents of anisodamine, anisodine, hyoscyamine and scopolamine were all improved in contrast to those in $\mathrm{BC}$ lines, respectively. These results showed that AaPMT gene in $\mathrm{P}$ lines has a positive influence on the flow of metabolites through TA biosynthesis pathway in A. acutangulus, which suggested that AaPMT gene is a new promising target site for metabolic regulation of tropane-alkaloid pathway in A. acutangulus [21]. However, overexpression of PMT gene in A. belladonna and $H$. niger hairy root cultures have no significant promotion on accumulation of TA $[1,22]$, which may be due to species-related or different specific post-translational regulation of the native enzyme in respect to the foreign one [23]. Sometimes, genetic manipulation of single enzymes to increase flux through the pathway may display various and even paradox results between different species [24].
The yield of TA in T lines was higher than the control and even P lines, which accounted for that AaTRI gene is a more effective regulatory target than $A a P M T$ gene for improving metabolic flux in TA biosynthetic pathway. The average content of TA in T lines $(1.682 \mathrm{mg} / \mathrm{g}$ $\mathrm{dw})$ were higher than that in P lines $(1.558 \mathrm{mg} / \mathrm{g} \mathrm{dw})$ or $\mathrm{BC}$ lines $(0.935 \mathrm{mg} / \mathrm{g} \mathrm{dw})$. So strong expression of AaTRI T in A. acutangulus hairy roots could up-regulate content of TA [19]. As shown in Figure 1, two tropinone reductases (TRI and TRII) formed the branching point of tropane alkaloid biosynthesis. High expression of TRII gene would lead to increasing accumulation of calystegines in the roots; while strong expression of TRI gene was accompanied with increased level of TA and decreased level of calystegine [25]. In a word, high TRI activity in $\mathrm{T}$ lines has positive effect on the conversion from pseudotropine to tropine, which would provide more key precursor for synthesis of TA.

Overexpression of single gene encoding a key enzyme may increase flux through the pathway, but its effect may be limited by other rate-committee step to some 


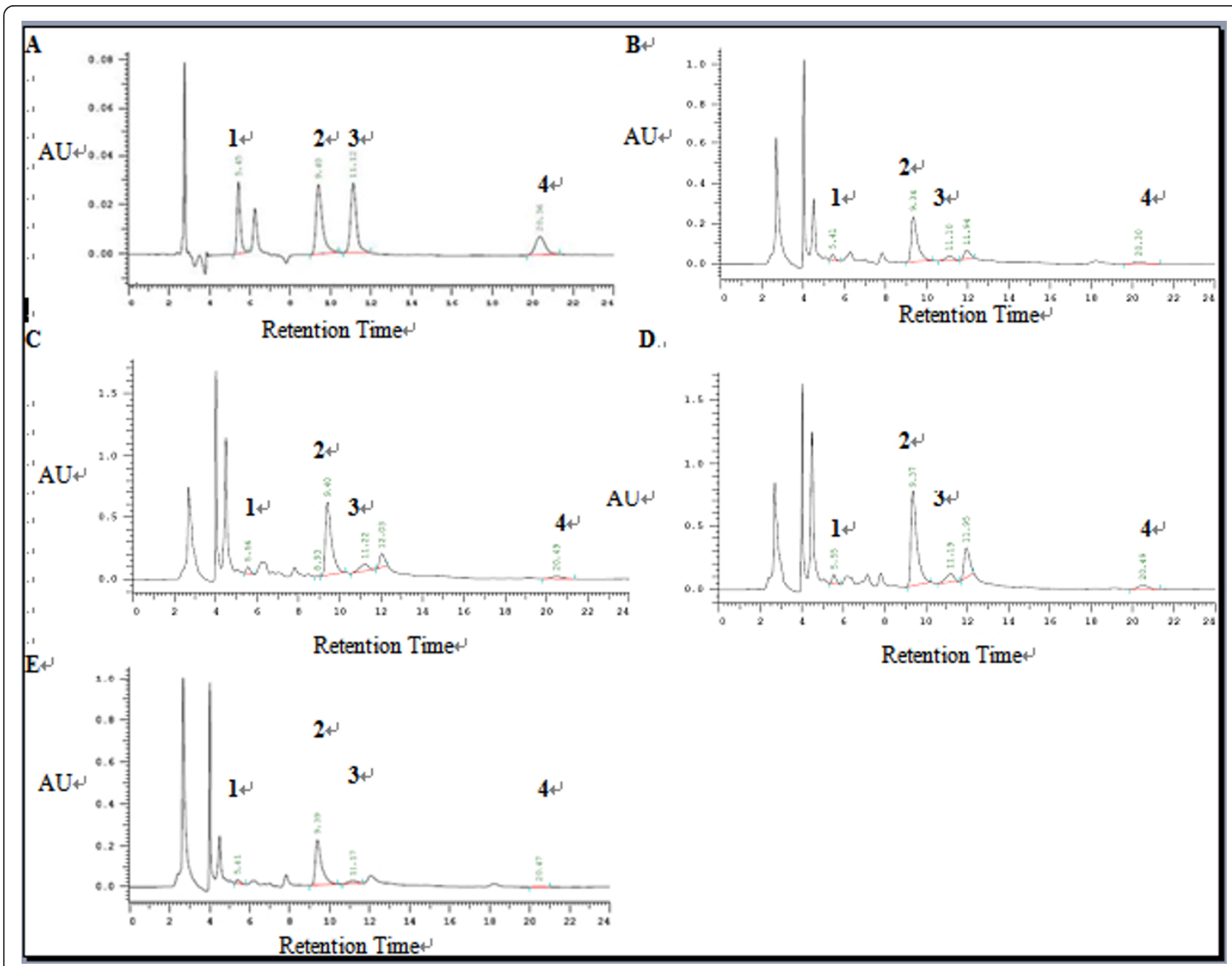

Figure 5 HPLC chromatograms of TA. A) mixture of standards of anisodamine, hyoscyamine, anisodine and scopolamine. B) HPLC chromatograms of TA in line P3. C) HPLC chromatograms of TA in line T12. D) HPLC chromatograms of TA in line PT18. E) HPLC chromatograms of TA in line BC1 (TA peaks, 1 for anisodamine, 2 for hyoscyamine, 3 for anisodine and 4 for scopolamine).

degree. Therefore, regulation of two or multiple genes would be more suitable to achieve significant gains in product accumulation. This may especially be true in branched pathways in which precursors can be channeled into a variety of metabolites away from the desired product [24]. In our work, line PT18 was the most successful one for production of TA, which was attributed to co-overexpression of two key genes (AaPMT and AaTRI). These results showed AaPMT and AaTRI make cooperative effect than single gene in the accumulation of TA in PT lines. In the hairy root lines, overexpressing upstream key enzyme and downstream branch-controlling enzyme may act as a push-pull effect in which flux is pushed toward the branch point by AaPMT and then pulled toward the desired product by AaTRI (Figure 1).

The DPPH (1,1-Diphenyl-2-picrylhydrazyl) radical scavenging activity, based on the reduction of the stable radical DPPH to yellow-colored diphenylpicrylhydrazine

Table 2 The average productions of transgenic lines.

\begin{tabular}{cccccc}
\hline & Anisodamine & Hyoscyamine & Anisodine & Scopolamine & Total TA \\
\hline P lines & $0.114 \pm 0.001$ & $1.300 \pm 0.006$ & $0.094 \pm 0.002$ & $0.0503 \pm 0.001$ & $1.558 \pm 0.036$ \\
T lines & $0.141 \pm 0.010$ & $1.376 \pm 0.03$ & $0.104 \pm 0.004$ & $0.0611 \pm 0.011$ & $1.682 \pm 0.050$ \\
PT lines & $0.193 \pm 0.01$ & $1.914 \pm 0.021$ & $0.167 \pm 0.005$ & $0.120 \pm 0.003$ & $2.395 \pm 0.016$ \\
\hline BC lines & $0.0738 \pm 0.0005$ & $0.829 \pm 0.047$ & $0.0218 \pm 0.0003$ & $0.0106 \pm 0.0005$ & $0.935 \pm 0.051$ \\
\hline
\end{tabular}

The average productions of anisodamine, hyoscyamine, anisodine, scopolamine and total TA among various transgenic hairy root lines (content unit: $\mathrm{mg} / \mathrm{g}$ dry weight) 


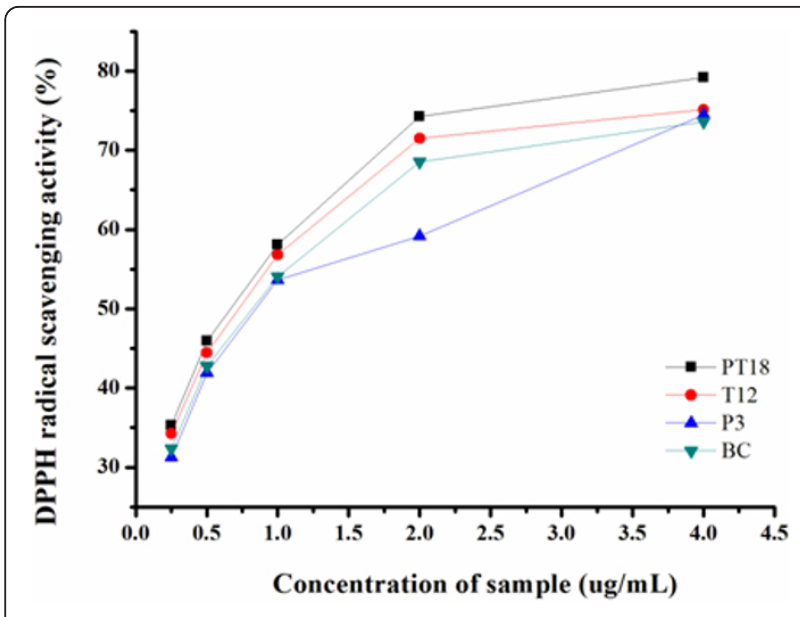

Figure 6 DPPH scavenging activities of methanolic TA from four different hairy root lines (P3, T12, PT9 and BC). Results represent means \pm standard deviation $(n=3)$.

in the presence of a hydrogen donor, was widely used to evaluate the antioxidant activity due to its advantage of rapid and simple measure [26]. TA has shown to possess the antioxidant activities [27]. The antioxidant activity of TA from hairy roots was estimated by measuring DPPH radical scavenging in this study. All the tested samples were found to possess strong radical scavenging capacity, which suggested that there were no significant differences among them. It indicated that antioxidant activity of aliquots of TA remained stable, so transgenic hairy root lines P3, T12 and PT18 showed higher total antioxidant activity of TA due to higher total TA content they produced.

Hyoscyamine-6-hydroxylase $(\mathrm{H} 6 \mathrm{H})$ catalyzes the oxidative reactions in the biosynthetic pathway leading from hyoscyamine to scopolamine and is also an effective regulatory site for the synthesis and accumulation of TA $[1,20]$. Therefore, in order to enhance the levels of TA and the capacity to convert hyoscyamine to much more scopolamine and anisodine, co-overexpression of multiple biosynthetic genes such as AaPMT, AaTRI and AaH6H in $A$. acutangulus may be a new promising strategy in the near future. In addition, anisodine is also an imperative tropane alkaloid in the market, which was first produced in hairy root cultures. This result suggested anisodine could be biosynthesized by TA biosynthesis pathway, which provided helpful information for our ensuing research.

\section{Conclusion}

In the present study, co-overexpression of $A a P M T$ and AaTRI genes in A. acutangulus hairy roots led to significantly increased production of four kinds of TA and showed higher antioxidant activity than control because of higher total TA content. This is the first report on simultaneous introduction of PMT and TRI genes into TA-producing plant using biotechnological methods. Our study results showed that transgenic hairy root culture system is a promising approach for improvement and large-scale production of TA in the future.

\section{Methods}

\section{Construction of Plant Expression Vectors}

The vectors pBI121 (Clontech) and pCAMBIA1304 (CAMBIA) were double-digested with HindIII and EcoRI. The purified smaller DNA fragment containing a GUS expression cassette from pBI121 was cloned into the large pCAMBIA1304 fragment to generate the recombinant plasmid pCAMBIA $1304^{+}$[19]. The fulllength AaPMT cDNA was inserted into pCAMBIA1304 ${ }^{+}$in place of the $m G F P 5$ and GUSA genes to generate pCAMBIA $1304^{+}-A a P M T$ expression vector containing AaPMT gene under the digestion of BgLII and BstEII (Takara Biotech Co., Ltd) (Figure 7A). Similarly, the pCAMBIA1304 ${ }^{+}$-AaTRI was also constructed in place of the $m G F P 5$ and GUSA genes under the digestion of $B g L I I$ and BstEII (Figure 7B). On the basis of pCAMBIA $1304^{+}-A a T R I$, the full-length AaPMT cDNA was used to replace GUS gene in pCAMBIA1304 ${ }^{+}$-AaTRI under the digestion of SacI and BamHI (Takara Biotech Co., Ltd) to generate the expression vector pCAMBIA $1304^{+}$-AaPMT-AaTRI containing both AaPMT and AaTRI genes (Figure 7C). The genes AaPMT or/and $A a T R I$ were under the control of strong cauliflower mosaic virus (CaMV) 35S promoter. The blank vector pCAMBIA1304 ${ }^{+}$without exogenous gene (such as AaPMT or AaTRI) was used as the control.

\section{Plant Transformation and Root Cultivation}

The disarmed A. tumefaciens strain C58C1 harbouring both the A. rhizogenes Ri plasmid pRiA4 [19] and each of the four plasmids constructed above, were used for plant genetic transformation. Different explants including leaf blades, petioles or stems were isolated from 4week-old in vitro grown sterile seedlings of $A$. acutangulus (Figure 8). The isolated explants were cut into small pieces (about $1 \mathrm{~cm}, 20$ pieces per dish) followed by preincubation on hormone-free MS containing $8.0 \mathrm{~g} / \mathrm{L}$ agar plates in the dark for 2 days, and then inoculated with C58C1 bacterial strain for 15 minutes. The explants were dried by blotting with sterile filter paper and then placed back on their original culture plates for cocultivation in the dark for 2 days. Then, the explants were rinsed with sterile water, and transferred onto B5 medium supplemented with $500 \mathrm{mg} / \mathrm{L}$ cefotaxime sodium to eliminate the residual Agrobacterium, $0.5 \mathrm{mg} / \mathrm{L}$ hygromycin to select positive hairy roots. The apical tips of hairy root induced from transformed explants were excised and sub-cultured on B5 solid medium with 500 


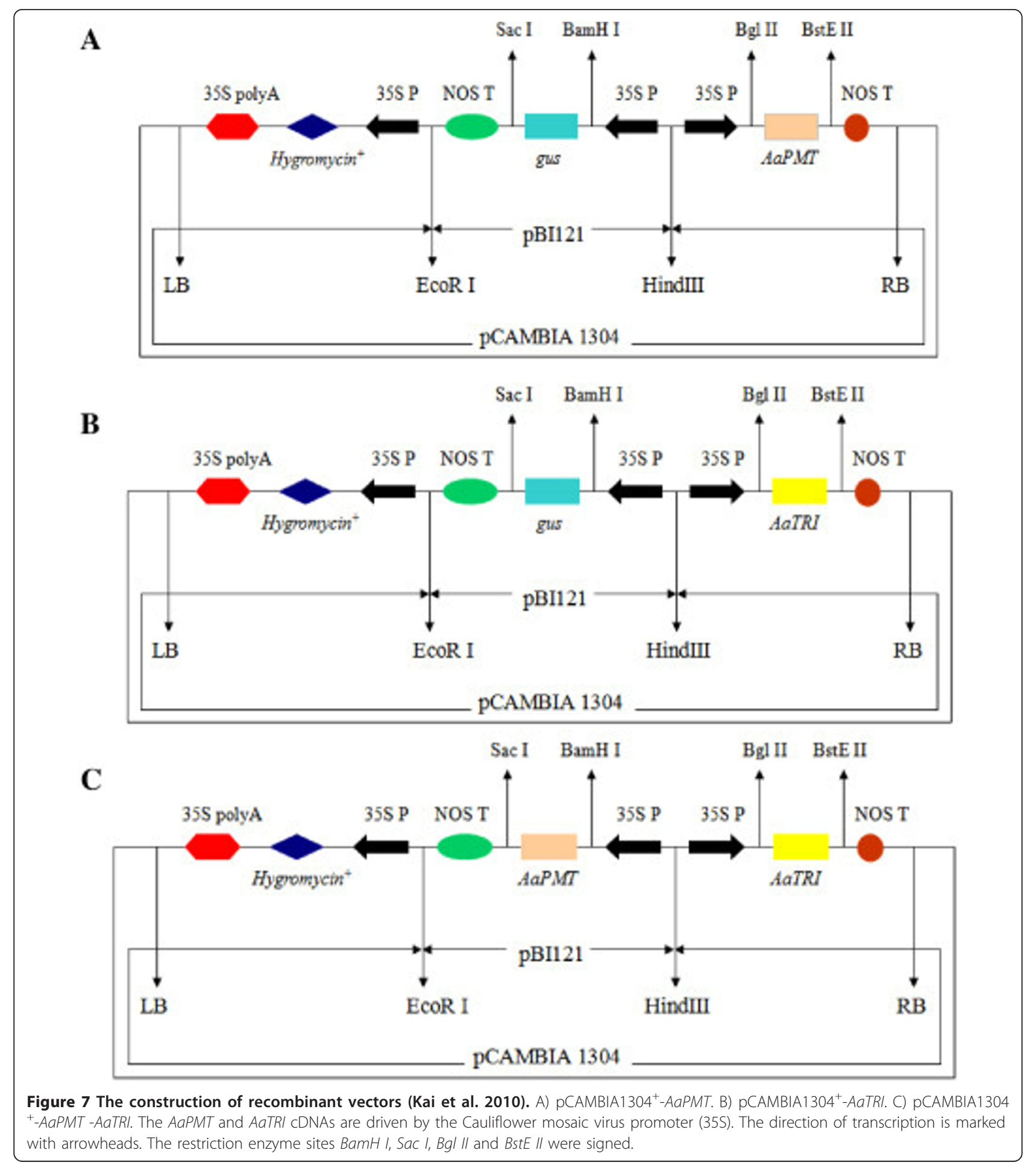

$\mathrm{mg} / \mathrm{L}$ cefotaxime at 2 -week intervals, the concentration of cefotaxime was gradually lowered and finally omitted after 3 months. When cultures had been cleared of Agrobacterium, hairy roots were transferred onto hormone-free B5 solid medium without cefotaxime [19,28].

\section{DNA extraction and PCR analysis}

When the engineered hairy roots grew to about $5 \mathrm{~cm}$, genomic DNA was isolated from hairy root samples by using DNA pure Plant Kit (Tiangen Biotech Co., Ltd, Beijing, China), which was used in PCR analysis for 


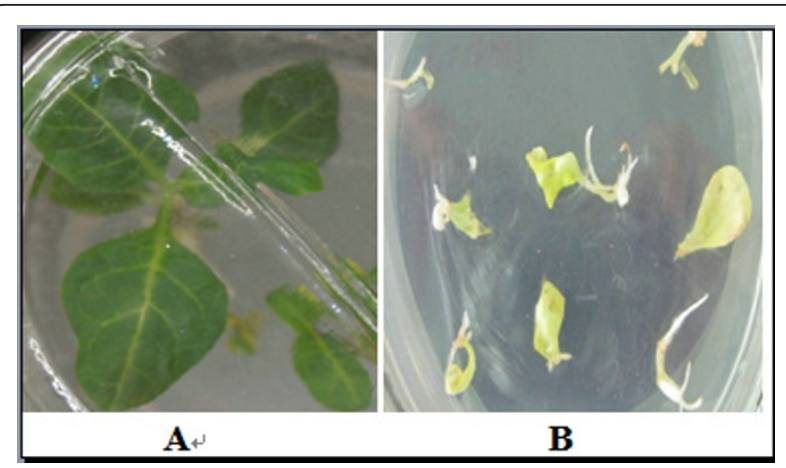

Figure 8 The explant used for hairy root induction.

detecting the presence of AaPMT and/or AaTRI in transgenic hairy root cultures (Table 3).

RNA extraction and gene expression analysis by RT-PCR and real-time fluorescence quantitative analysis

The transgenic hairy roots identified by PCR analysis were chosen and inoculated into $150 \mathrm{~mL}$ 1/2MS liquid nutrient media ( $\mathrm{pH} 5.8$ ) in $250 \mathrm{~mL}$ conical flasks on a gyratory shaker operating at $100 \mathrm{rpm}$ at $27^{\circ} \mathrm{C}$ in darkness for RT-PCR and real-time fluorescence quantitative after 60 days' culture. RNA was extracted using RNA pure Plant Kit (Tiangen Biotech Co., Ltd, Beijing, China) following the manufacture's instructions. RNA was quantified using spectrophotometric measurements and kept at $-80^{\circ} \mathrm{C}$ for further analysis [29]. Aliquots of total RNA $(1 \mu \mathrm{g})$ was used as a template to generate cDNA using avian myeloblastosis virus (AMV) reserve transcriptase (Promega, USA) and then for further semiquantitative RT-PCR to quantify gene expression profiles of different samples. RT-PCR was carried out using similar procedure as reported before [3,19]. AaPMTKF and AaPMTKR, AaTRIKF and AaTRIKR (Table 4) were used to detect the expression of total (including native and introduced cDNA) AaPMT and AaTRI genes, whereas AaPMTKF and AaPMT 3'-UTR; AaTRIKF and AaTRI 3'-UTR (Table 5) were only used for the expression profiles of native AaPMT and AaTRI genes, respectively. Meanwhile, RT-PCR with primers 18 SF (5'CCAGGTCCAGACATAGTAAG-3') and 18SR (5'-GTACAAAGGGCAGGGACGTA-3'), designed on the basis of the conserved regions of plant house-keeping genes

Table 3 Primer Pairs Employed for the PCR Amplification of TA Biosynthetic Genes AaPMT and AaTRI

\begin{tabular}{ll}
\hline $\begin{array}{l}\text { Primer Pairs } \\
\text { (Reverse) }\end{array}$ & \\
\hline AaPMT & $\begin{array}{l}\text { Forward: 5'ATGGAGGTCATAAGCAACCAC-3' } \\
\text { Reverse: 5'-TCAAAATTCAACCAAATCCC-3' }\end{array}$ \\
\hline AaTRI & Forward: 5'-ATGGGAGAATCAAAAGTTTACAT-3' \\
& Reverse: 5'-TCAAAATCCACCATTAGCTGTGA-3' \\
\hline
\end{tabular}

Table 4 Primer Pairs Employed for the RT-PCR Amplification of Total Biosynthetic Genes AaPMT and AaTRI

\begin{tabular}{ll}
\hline $\begin{array}{l}\text { Primer Pairs: } \boldsymbol{K} \boldsymbol{F} \text { of AaPMT, AaTRI(Forward) and } \boldsymbol{K} R \text { of AaPMT, AaTRI } \\
\text { (Reverse) }\end{array}$ \\
\hline AaPMT & $\begin{array}{l}\text { Forward: 5'-ATGGAGGTCATAAGCAACCAC-3' } \\
\text { Reverse: 5'-TCAAAATCAACCAAATCCC-3' }\end{array}$ \\
\hline AaTRI & $\begin{array}{l}\text { Forward: 5'-ATGGGAGAATCAAAAGTTACAT-3' } \\
\text { Reverse: 5'-TCAAAATCCACCATAAGCTGTGA-3' }\end{array}$ \\
\hline
\end{tabular}

(18S rRNA genes), was also performed to normalize equal amounts of RNA among samples as an internal standard [30,31]. Gene-specific primers were designed using primer Express 3 (Applied Biosystem Co., Ltd, USA) for real-time fluorescence quantitative: AaPMT26F (5'-TGGCAGCACCACCAAAATTA-3') and AaPMT163R (5'-TGGCCAGAGTGCGCTAAACT-3') to detect the expression level of AaPMT, AaTRI515F (5'-TGCTTCCAAAGCTGCAATAA-3') and AaTRI595R (5'-TAAAATGATTCCCGGAGCAA-3') to detect the expression level of AaTRI, and 18SF' (5'-GCCTTCGGGATCGGAGTAAT-3') and 18SR' (5'CCCCCAACTTTCGTTCTTGA-3') to detect the expression level of $18 S$ (plant house-keeping gene). Real-time RT-PCR analysis was performed in an Applied Biosystem StepOne (Applied Biosystem Co., Ltd, USA). The relative $\mathrm{Ct}$ (threshold cycle value) method was used to estimate the initial amount of template present in the reactions by Applied Biosystems SDS 2.0.

TA production in transgenic $A$. acutangulus hairy roots by HPLC analysis

The extraction of TA was conducted using the method reported previous [26]. After extraction, HPLC analysis was performed on a HITACHI L2000 HPLC system equipped with a photodiode array detector. The separation of TA was carried out on a reversed-phase symmetry column $(250 \mathrm{~mm} \times 4.6 \mathrm{~mm} ; 5 \mu \mathrm{m})$. The mobile phase consisted of $22 \%$ acetonitrile (HPLC grade) and $78 \%$ diethylamin buffer (containing 0.7\% diethylamine and adjust $\mathrm{pH}$ to 7.2 with orthophosphoric acid). The flow rate was $1.0 \mathrm{~mL} / \mathrm{min}$ and the injection volume was $20 \mu \mathrm{L}$. Four TA compounds including anisodamine, hyoscyamine, anisodine and scopolamine were detected

Table 5 Primer Pairs Employed for the RT-PCR Amplification of Native Biosynthetic Genes AaPMT and AaTRI

\begin{tabular}{ll}
\hline $\begin{array}{l}\text { Primer Pairs } K \boldsymbol{K} \text { of AaPMT, AaTRI (Forward) and 3'UTR of AaPMT, } \\
\text { AaTRI }\end{array}$ \\
\hline AaPMT & Forward: 5'-ATGGAGGTCATAAGCAACCAC-3' \\
& 3-UTR 156R: 5'-ATATCAGTTATTGCATTATAC-3' \\
\hline AaTRI & Forward: 5'-ATGGGAGAATCAAAAGTTACAT-3' \\
& 3-UTR 244R:5'-TTGCGACATTTATTGTGATGA-3' \\
\hline
\end{tabular}


and quantified by comparison with authentic standard curves and retention times.

\section{Measurement of DPPH free-radical scavenging activity} The free radical scavenging activity of TA from transgenic hairy roots (P3, T12, PT18 and BC) was measured by the DPPH method reported by Adeolu et al. (2008) with slight modifications [32]. Briefly, the different concentration $(0.25-4 \mu \mathrm{g} / \mathrm{mL})$ of $1 \mathrm{~mL}$ of each sample was added to $1 \mathrm{~mL} \mathrm{DPPH}(0.2 \mathrm{mM})$ solution in methanol. The tubes with reaction mixture were vortexed thoroughly and incubated at room temperature for $30 \mathrm{~min}$. Spectrophotometer was used to detect the absorbance of the mixture at $517 \mathrm{~nm}$. The DPPH solution in methanol $(0.2 \mathrm{mM})$ was used as the control. Radical scavenging activity of TA was calculated according to the following formula: DPPH radical scavenging activity $(\%)=[1$ absorbance of the sample/absorbance of the control] $\times 100$.

\section{Statistical analysis}

All the experiments including PCR identification, semiquantitative RT-PCR, HPLC and measurement of antioxidant activity were repeated three times. Analysis was repeated three times. Results of TA content are presented as mean values \pm S.D. The statistical significance of TA difference was analyzed by one sample $t$ test using SPSS software (SPSS, Inc.).

\section{Acknowledgements}

This work was supported by Key Science and Technology Brainstorm Project of Yangtze River Delta (10140702018), National Transgenic Organism New Variety Culture Key Project (2009ZX08012-002B), National Natural Science Fund (30900110), Shanghai Science and Technology Committee Project (10JC1412000, 09QH1401900, 06QA14038, 08391911800, 073158202, 075405117, 065458022, 05ZR14093), Shanghai Education Committee Fund (09ZZ138, 06DZ015), Zhejiang Provincial Natural Science Fund (Y2080621), Fujian Science and Technology Committee Key Special Project (2008NZ00014), Leading Academic Discipline Project of Shanghai Municipal Education Commission (J50401), Project from Shanghai Normal University (SK200830, CH030). Miss Pin Liu's (Shanghai Jiaotong University, China) kind assistance with HPLC analysis is also acknowledged.

\section{Authors' contributions}

GK designed the study, performed the experiments and revise the manuscript. SY performed the experiments, analyzed the data and draft the manuscript. XL, WZ, XF, AZ and $Y Z$ helped to culture hairy roots. JX helped to direct data analysis. All authors read and approved the final manuscript.

Received: 16 October 2010 Accepted: 28 April 2011

Published: 28 April 2011

\section{References}

1. Zhang L, Ding RX, Chai YR, Bonfill M, Piñol MT, Xu TF, Pi Y, Wang ZN, Zhang HM, Kai GY, Liao ZH, Sun XF, Tang KX: Engineering tropane biosynthetic pathway in Hyoscyamus niger hairy root cultures. Proc Natl Acad Sci USA 2004, 101:6786-6791.

2. Zayed R, Wink M: Induction of Tropane Alkaloid Formation in Transformed Root Cultures of Brugmansia suaveolens (Solanaceae). Z Naturforsch C 2004, 59(11-12):863-867.
3. Kai GY, Zhang Y, Chen JF, Li L, Yan XM, Zhang R, Liao P, Lu X, Wang W, Zhou GY: Molecular characterization and expression analysis of two distinct putrescine N-methyltransferases from roots of Anisodus acutangulus. Physiologia Plantarum 2009, 135:121-129.

4. Cardillo AB, María Otalvaro Alvarez A, Calabró Lopez A, Enrique Velásquez Lozano M, Rodríguez Talou J, María Giulietti A: Anisodamine Production from Natural Sources: Seedlings and Hairy Root Cultures of Argentinean and Colombian Brugmansia candida Plants. Planta Med 2009, 76(4):402-405.

5. Wang H, Zhang SH, Huang LS, Zhao RH, Wei HP: Protective effects of anisodine and anisodamine on acute lung injury induced by oleic acid in rats. Chinese Journal of Critical Care Medicine 1999, 19(11):663-664.

6. Wu GL, Zheng QY, Tian N: Protective Effects of Anisodine, Buscopan, Anisodamine on Acute Renal Failure with Dam-ages of Renal Microvessels in Rat. Chinese Journal of Microcirculation 2002, 12(1):6-8.

7. Guillon S, Trémouillaux-Guiller J, Pati PK, Rideau M, Gantet P: Hairy root research: recent scenario and exciting prospects. Curr Opin Plant Biol 2006, 9:341-346.

8. Wu JY, Shi M: Ultrahigh diterpenoid tanshinone production through repeated osmotic stress and elicitor stimulation in fed-batch culture of Salvia miltiorrhiza hairy roots. Appl Microbiol Biotechnol 2008, 78:441-448.

9. Yamada $Y$, Hashimoto T: Production of tropane alkaloids in cultured cells of Hyoscyamus niger. Plant Cell Rep 1982, 1:101-103.

10. Oksman-Caldentey KM, Kivel O, Hiltunen R: Spontaneousshoot organogenesis and plant regeneration from hairy root cultures of Hyoscyamus muticus. Plant Sci 1991, 78:129-136.

11. Sevón N, Oksman-Caldentey KM, Hiltunen R: Efficient plant regeneration from hairy root-derived protoplasts of Hyoscyamus muticus. Plant Cell Rep 1995, 14:738-742.

12. Sevón N, Dräger B, Hiltunen R, Oksman-Caldentey KM: Characterization of transgenic plants derived from hairy roots of Hyoscyamus muticus. Plant Cell Rep 1997, 16:605-611.

13. Kai GY, Chen JF, Li L, Zhou GY, Zhou LM, Zhang L, Chen YH, Zhao LX: Molecular cloning and characterization of a new cDNA encoding hyoscyamine $6 \beta$-hydroxylase from roots of Anisodus acutangulus. Journal of Biochemistry and Molecular Biology 2007, 40(5):715-722.

14. Yun DJ, Hashimoto T, Yamada Y: Metabolic engineering of medicinal plants: transgenic Atropa belladonna with an improved alkaloid composition. Proc Natl Acad Sci USA 1992, 89:11799-11803.

15. Leonard E, Runguphan W, O'Connor S, Prather KJ: Opportunities in metabolic engineering to facilitate scalable alkaloid production. Nat Chem Biol 2009, 5(5):292-300.

16. Wu DK, Wang FL, Chen ZR, Yang JS, Huang QL: Chemical analysis of Anisodus acutangulus in Yunnan and extraction of atropine sulphate. Med Pharm Yunnan 1962, 3:67-68.

17. Leech MJ, May K, Hallard D, Verpoorte R, Luca VD, Christou P: Expression of two consecutive genes of a secondary metabolic pathway in transgenic tobacco: molecular diversity influences levels of expression and product accumulation. Plant Mol Biol 1998, 38:765-774.

18. Oksman-Caldentey KM, Arroo R, Verpoorte R, Alfermann AW, (Kluwer the Netherlands): Metabolic Engineering of Plant Secondary Metabolism, eds 2000, 254-281.

19. Kai GY, Li L, Wang J, Zhang Y, Zhang R, Yan XM, Liao P, Lu X, Wang W, Lu Y, Zhou GY: Molecular cloning, characterization of two tropinone reductases in Anisodus acutangulus and enhancement of tropane alkaloids production in AaTRI-transformed hairy roots. Biotechnol Appl Biochem 2009, 54(3):177-186.

20. Jouhikainen $K$, Lindgren $L$, Jokelainen T, Hiltunen R, Teeri TH, OksmnCaldentey K-M: Enhancement of scopolamine production in Hyscyamus muticus L. hairy root cultures by genetic engineering. Planta 1999, 208:545-551.

21. Moyano E, Jouhikainen K, Tammela P, Palazón J, Cusidó RM, Piñol MT, Teeri TH, Oksman-Caldentey KM: Effect of pmt gene overexpression on tropane alkaloid production in transformed root cultures of Datura metel and Hyoscyamus muticus. J Exp Bot 2003, 54(381):203-211.

22. Sato F, Hashimoto T, Haciya A, Tamura K, Choi K-B, Morishige T, Fujimoto H, Yamada Y: Metabolic enginneering of plant alkaloid biosynthesis. Proc Natl Acad Sci USA 2001, 98:367-372.

23. Moyano E, Fornalé S, Palazón J, Cusidó RM, Bagni N, Piñol MT: Alkaloid production in Duboisia hybrid hairy root cultures overexpressing the pmt gene. Phytochemistry 2002, 59:697-702. 
24. Peebles CA, Sander GW, Hughes EH, Peacock R, Shanks JV, San KY: The expression of 1-deoxy-d-xylulose synthase and geraniol-10-hydroxylase or anthranilate synthase increases terpenoid indole alkaloid accumulation in Catharanthus roseus hairy roots. Metab Eng 2010

25. Richter U, Rothe G, Fabian AK, Rahfeld B, Dräger B: Overexpression of tropinone reductases alters alkaloid composition in Atropa belladonna root cultures. J Exp Bot 2005, 56(412):645-52.

26. Wu YL, Wang DN: A New Class of Natural Glycopeptides with Sugar Moietydependent antioxidant activities derived from Ganoderma lucidum fruiting bodies. J Proteome Res 2009, 8(2):436-442.

27. Zhang B, Shi SB, Li HP, Han F: Comparison of Photosynthetic Pigment Contents and Antioxidase Activity of Anisodus tanguticus from Different Leaf Layers Grown at Two Altitudes Level in Qinghai-Tibet Plateau. Acto Bot Boreal-Occident Sin Chinese Journal 2008, 28(9):1778-1786.

28. Li L, Wang J, Wang W, Lu Y, Wang YL, Zhou GY, Kai GY: Optimization of Induction and Culture Conditions and Tropane Alkaloid Production in Hairy Roots of Anisodus acutangulus. Biotechnol Bioproc E 2008, 13:606-612.

29. EL Jaber-Vazdekis N, Barres ML, Ravelo AG, Zarate R: Effects of Elicitors on Tropane Alkaloids and Gene Expression in Atropa baetica Transgenic Hairy Roots. J Nat Prod 2008, 71(12):2026-2031.

30. Liao P, Zhou W, Zhang Lin, Wang J, Yan XM, Zhang Y, Zhang R, Li L, Zhou GY, Kai GY: Molecular cloning, characterization and expression analysis of a new gene encoding 3-hydroxy-3-methylglutaryl coenzyme A reductase from Salvia miltiorrhiza. Acta Physiol Plant 2009, 31:565-572.

31. Kai GY, Liao P, Zhang T, Zhou W, Wang J, Xu H, Liu YY, Zhang L: Characterization, Expression Profiling, and Functional Identification of a Gene Encoding Geranylgeranyl Diphosphate Synthase from Salvia miltiorrhiza. Biotechnol Bioproc E 2010, 15:236-245.

32. Adedapo AA, Jimoh FO, Koduru S, Afolayan AJ, Masika PJ: Antibacterial and antioxidant properties of the methanol extracts of the leaves and stems of Calpurnia aurea. BMC Complem Alt Med 2008, 8:53.

doi:10.1186/1472-6750-11-43

Cite this article as: Kai et al:: Co-expression of AaPMT and AaTRI effectively enhances the yields of tropane alkaloids in Anisodus acutangulus hairy roots. BMC Biotechnology 2011 11:43.

\section{Submit your next manuscript to BioMed Central and take full advantage of:}

- Convenient online submission

- Thorough peer review

- No space constraints or color figure charges

- Immediate publication on acceptance

- Inclusion in PubMed, CAS, Scopus and Google Scholar

- Research which is freely available for redistribution

Submit your manuscript at www.biomedcentral.com/submit
Biomed Central 